Article

\title{
Integrating Ecosystem Function and Structure to Assess Landscape Ecological Risk in Traditional Village Clustering Areas
}

\author{
Sheng Liu ${ }^{1,2}, * \mathbb{D}$, Ming Bai ${ }^{3}$ and Min Yao ${ }^{3}$ \\ 1 Department of Environment Design, Zhejiang University City College, Hangzhou 310011, China \\ 2 College of Civil Engineering and Architecture, Zhejiang University, Hangzhou 310058, China \\ 3 Urban-Rural Planning \& Design Institute, Zhejiang University, Hangzhou 310030, China; \\ 3120102646@zju.edu.cn (M.B.); 11912123@zju.edu.cn (M.Y.) \\ * Correspondence: lius@zucc.edu.cn
}

Citation: Liu, S.; Bai, M.; Yao, M. Integrating Ecosystem Function and Structure to Assess Landscape Ecological Risk in Traditional Village Clustering Areas. Sustainability 2021, 13, 4860. https://doi.org/10.3390/ su13094860

Academic Editor: Carmela Cucuzzella

Received: 1 March 2021

Accepted: 22 April 2021

Published: 26 April 2021

Publisher's Note: MDPI stays neutral with regard to jurisdictional claims in published maps and institutional affiliations.

Copyright: (c) 2021 by the authors. Licensee MDPI, Basel, Switzerland. This article is an open access article distributed under the terms and conditions of the Creative Commons Attribution (CC BY) license (https:// creativecommons.org/licenses/by/ $4.0 /)$.

\begin{abstract}
Land use in traditional village clustering areas often exhibits slight dynamic changes; however, significant hidden ecological hazards may be present in local settlements. There is still a lack of dynamic ecological risk assessments for the corresponding classification-based prevention strategies and landscape ecosystem attributes' enhancement. Based on the land-use changes, this study integrated the ecosystem structure and function to explore the characteristics of the landscape ecological risk in traditional village clustering areas. The clustering area of 24 national traditional villages in Songyang County of Lishui City in Zhejiang Province, China, served as the study region to evaluate and analyze the changes in the landscape ecological risk from 2010 to 2019. The results showed that the land-use transitions were subtle but dominated by changes from forest cultivated land, posing high risk and medium—high risk increased slowly in size. Additionally, significantly increased risks were located mainly in the boundary area of the five villages. Moreover, 22 settlements were found in the sensitive area with increased risks less than $600 \mathrm{~m}$ away. This assessment will provide a basis for traditional villages' risk prevention and ecosystem protection.
\end{abstract}

Keywords: ecological risk; ecosystem function; ecosystem structure; traditional village

\section{Introduction \\ 1.1. Background}

Traditional villages are usually villages with cultural heritages that take both material and non-material forms; these villages offer non-renewable historical, cultural, architectural, and research value [1]. In 2012, China started protecting single traditional villages, and in 2019, the protected objects expanded from single villages to village clusters, focusing on the sustainable and healthy development of contiguous villages. Traditional village cluster areas (TVCA) are delineated by Chinese local governments, according to the protection boundary of the contiguous villages with high protection values [2]. They are not administrative units but are of management significance for centralized protection and revitalization.

The term landscape emerged around the sixteenth century, referring to the natural scenery in paintings [3]. From an ecological aspect, landscapes are spatially heterogeneous geographical areas characterized by diverse interacting ecosystems, ranging from relatively natural terrestrial to human-dominated environments [4,5]. In TVCA, the landscape connects and protects each settlement's living systems, and its sustainability is of great significance in ensuring a contiguous inheritance [6].

However, due to different land policies in China, land use in TVCA is changing at the microlevel. In some cases, due to the balance of arable land systems (BALSs) and the Low-Yield Forest Reconstruction Project, some forest land has been turned into cultivated 
land [7]. Other areas have benefited from the Grain-for-Green Project, leading to change from grassland to forest land [8]. These changes are usually subtle and not easy to perceive at the regional level; however, local dotted changes can easily cause major disasters for settlements, threatening the sustainable survival of traditional villages. For example, in the Su village in Lishui City of Zhejiang Province, China, satellite images starting in 2000 showed a reduction in the dotted mountain forest land at the edge of the village and the expansion of a rock exposure every year. However, the government had no scientific method of predicting ecological risk, so risk was continuously not addressed, and forest land was continuously reduced. As a result, in 2016, a geological disaster occurred, damaging the traditional environment, causing 27 deaths, and damaging 20 houses [9].

Given this background, this study addressed a core problem. Land use in TVCA exhibits slight dynamic changes, easily hiding major ecological risks in local settlements. There is a lack of scientific research on the features of this ecological risk in TVCA for prioritizing risk avoidance. An appropriate dynamic risk assessment is needed to effectively avoid damage to its ecosystems and prevent the occurrence of other derivative disasters.

\subsection{Literature Review}

An ecosystem is a community of living organisms in conjunction with the nonliving components of their environment, interacting as a system [10]. It has many derivative concepts. For instance, a business ecosystem centers on a firm and its environment [11]; a soil ecosystem focuses on interaction among biomass, nutrient, and water [12]. A landscape ecosystem refers to the ecosystem at the landscape scale and is a hierarchical level of the ecosystem [13]. It is defined as the community developed through the interaction between the spatial and temporal patterns and the ecological processes [14].

Landscape ecological risk (LER) refers to the possible negative impact of the interaction between landscape pattern and ecological processes [15,16], while ecological risk is defined as the probability of occurrence of an undesired ecological impact [17]. The main difference between ecological risk, which frequently assumes that systems are spatially homogeneous, and landscape ecological risk is that the latter considers the spatial patterns and heterogeneity [18]. Past studies on landscapes in traditional villages have mostly focused on tourism development and forest management [19-21]. They have not fully addressed ecological risk in TVCA. Additionally, existing LER models have mainly focused on the cities, rivers, and roads [22-24], or areas delineated as a world cultural heritage area with a high protection value [25]. As the characteristics of these risks differ from those found in traditional villages, there is still a gap in this special LER assessment.

The index method is the common method for conducting an LER assessment [24,26]. It is based on land use analysis and is constructed through the degree of landscape disturbance and fragility, using the paradigm of "multiplicative multiplication of loss and probability" to depict the spatial-temporal heterogeneity of risks. However, this method only uses the proportion of different land-use areas as the weight, leading to a lack of representation of ecological factors in risk probabilities [27]. Meanwhile, some studies have applied a "source-sink" method to evaluate specific risk sources, such as population growth and heavy metal contamination [28,29]. However, as this method is difficult to characterize the risk status of multisource stress, it reflects the comprehensive characteristics of LER in a relatively weak manner. Given the challenges associated with existing methods, the need for more feasible quantitative evaluation methods is highlighted.

In summary, this study has addressed the following knowledge gaps: (1) Identifying the characteristics of the LER in TVCA; and (2) developing a comprehensive risk assessment method that can reflect both the multisource stress and the internal changes in the traditional villages' landscape ecosystems. Solving these gaps could lead to the development of a scientific basis for prioritizing management practices that prevent and control ecological risks in TVCA. 


\section{Methods}

\subsection{Study Area}

There are 6819 national-level traditional villages in China. Most are located in mountainous areas, with abundant forest and grassland resources, and are densely distributed in Guizhou, Yunnan, Hunan, and Zhejiang [30]. The middle area of Songyang County, Lishui City, Zhejiang Province in China was selected as the study area, and 24 national-level traditional village clustering areas in 6 townships were selected as the evaluation area, covering $114.39 \mathrm{~km}^{2}$ (Figure 1). According to the hierarchical framework of ecological units [31], this size of landscape belongs to the subregion scale, referring to the county level.
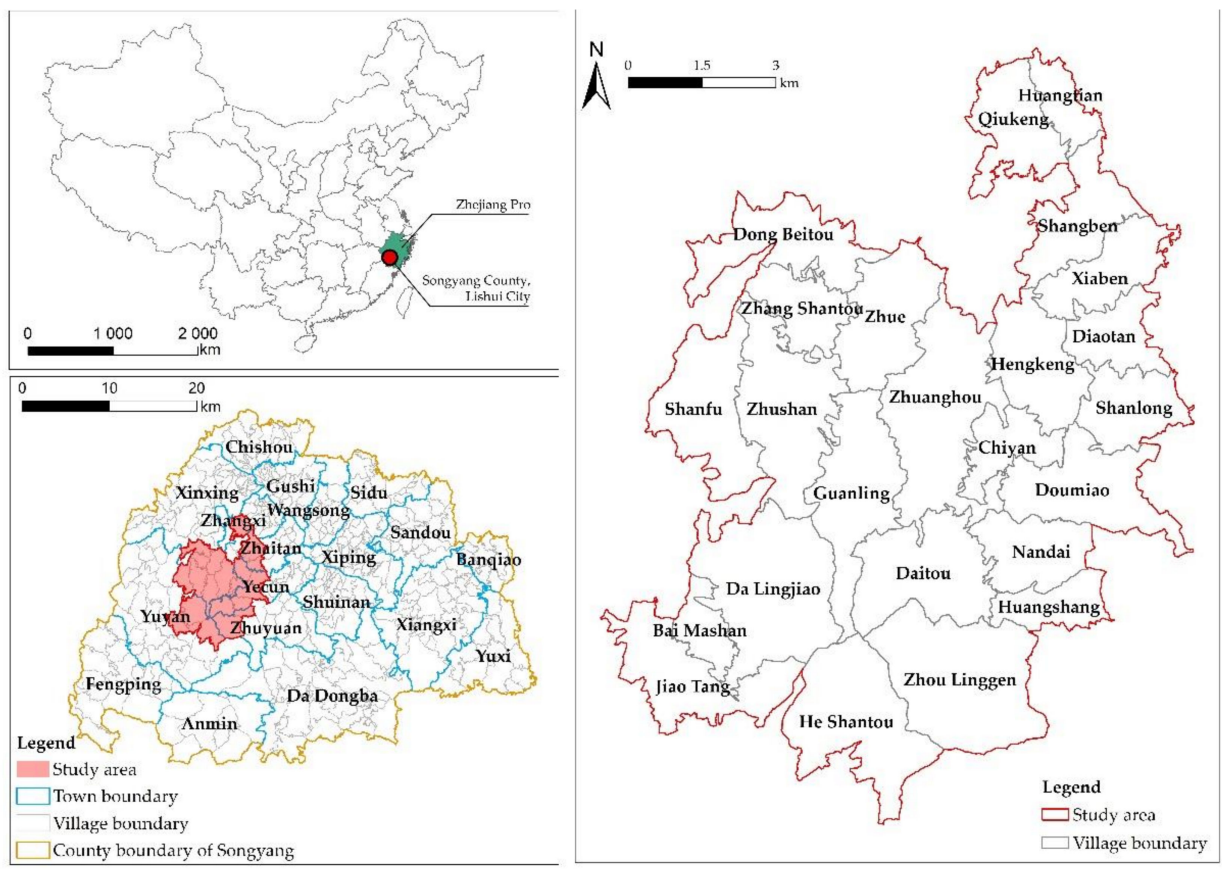

Figure 1. Study area.

Zhejiang has a high level of economic development in China and has experienced significant changes in its land use. Lishui City is the area where the forest hand has decreased the most in Zhejiang Province [7]. Songyang County is the first demonstration county for protecting and utilizing traditional villages in China. It is also the county with the fifth largest number of traditional villages in China (the county is ranked first concerning this count in Zhejiang Province). As a result, there are many areas with contiguous traditional village clusters in Songyang County, making it a typical area for research.

The study area is dominated by mid-sized mountains and hills and belongs to the subtropical monsoon climate zone, with an average annual temperature of $17.9^{\circ} \mathrm{C}$. The land use types mainly include forest land, supplemented by cultivated land. The BALS and the rewarded land conversion quotas (RLCQ) trade policy, which allow the localities with land scarcity in Zhejiang province to buy cultivated land quotas from those with plenty of land endowments [32], has led to frequent deforestation for farmland construction around traditional villages with low economic income and abundant forest land resources. It has resulted in the heterogeneity of risks, which has led to a higher need to classify the dynamic change associated with ecological risk, making the area effective for the research purpose.

\subsection{Methods}

The object of the LER assessment is the landscape ecosystem, as many studies have shown that land-use changes can pose risks to ecosystem structure and function at the landscape level $[33,34]$. Thus, we believed the land-use changes threatened the structure and function of the landscape ecosystem in the TVCA. These two attributes reflect different 
properties of ecosystems, which cannot replace each other and have the same importance. Thus, in conducting the comprehensive evaluation, considering the same weight of these two aspects, the formula for the LER is as follows:

$$
L E R=0.5 E S+0.5 E F
$$

where LER denotes landscape ecological risk; ES denotes ecosystem structure; and EF denotes ecosystem function. The specific methods for assessing $E S$ and $E F$ are as follows.

\subsubsection{Ecosystem Structure}

Ecosystem structure includes the physical features and organisms of an environment $[35,36]$. In this study, we considered the $E S$ as the environment's physical features in horizontal space, because at the landscape scale, land-use change can pose risks to its physical stability, spatial continuity, and anti-interference, which can be represented respectively by the degree of fragmentation $(D F)$, degree of division $(D D)$, and dominance of landscape $(D L)$ (an index representing the spatial balance of its patches; the higher the degree of dominance, the lower the balance and the anti-interference ability) [15]. The specific formula is as follows [37-39]:

$$
\begin{gathered}
E S=a C_{i}+b N_{i}+c D_{i} \\
C_{i}=\frac{n_{i}}{A} \\
N_{i}=1-\sum_{i=1}^{m} \sum_{j=1}^{n}\left(\frac{a_{i j}}{A}\right)^{2} \\
\max _{j} \frac{a_{i j}^{\prime}}{A}
\end{gathered}
$$

where $C_{i}, N_{i}$, and $D_{i}$ denote $D F, D D$, and $D L$ of land use type $i$, respectively. These factors have different units, so they are normalized before being summed. The parameters $a, b$, and $c$ denote the weight of each index, reflecting the effects of human activities on landscape ecosystems. This study evaluated these three indicators as $0.5,0.3,0.2$, respectively, as they have been commonly assigned in previous studies [39,40]. Meanwhile, the variable $n_{i}$ is the number of patches in the land use type $i$; the patch is a piece of land with relatively homogeneous land use that differs from its surroundings; A is the total area of the whole region; $a_{i j}$ denotes the area of the jth patchin the land use type $i$; and $a_{i j}^{\prime}$ denotes the patch with the largest area in the sample area.

The grid sampling method was used to calculate ES. Existing studies have pointed out that the area of the sample unit should be $2-5$ times the average patch area to effectively reflect the information on $E S$ around sampling sites [41,42]. Therefore, in this study, the risk area division was performed using systematic sampling based on the average area of patches in the case study area. The sampling unit was $300 \mathrm{~m} \times 300 \mathrm{~m}$, and there was a total of 1271 quadrates (Figure 2). The software package Fragstats 4.2 was used to calculate the $E S$ index for each quadrat. The $E S$ value of each quadrate was set as the attribute value for its center point, and the Kriging interpolation method was used to obtain the spatial distribution of ES in the study area using the geostatistical analyst of ArcGIS 10.6.

\subsubsection{Ecosystem Function}

Land-use changes can pose risk to $E F$ in terms of its carbon cycle regulation, water regulation, and air regulation, which can be represented respectively by carbon sequestration $(C S)$, the runoff curve number $(C N)$, and vegetation coverage $(V C)$ [43]. As the three regulation functions are considered to be of equal importance, the formulas for calculating EF are as follows [44-46]:

$$
E F=(C S+C N+V C) / 3
$$




$$
\begin{gathered}
\mathrm{CS}=\sum_{i=1}^{n} \frac{A_{i}}{A} * C_{i} \\
C_{i}=C_{v i}+C_{s i} \\
\mathrm{CN}=\sum_{i=1}^{n} \frac{A_{i}}{A} * C N_{i} \\
\mathrm{VC}=\sum_{i=1}^{n} \frac{A_{i}}{A} * V_{i}
\end{gathered}
$$

where $C S$ is the carbon sequestration, $C N$ is the curve number, and $V C$ is the vegetation coverage. Within the equations, $\mathrm{Ai}$ is the area of land use type I, A is the total area of the whole region, $C_{i}$ is the carbon density of land use type $i, C_{v i}$ is the vegetation carbon density, and $C_{s i}$ is the soil carbon density (See Table 1 for the $C S$ values for different types of land use). The variable $C N_{i}$ denotes the runoff index for land use type $i$, with the values listed in Table 2. The variable $V i$ denotes the vegetation index for land use type $i$, with the values listed in Table 3 . The variables CS, $C N$, and $V C$ have different measurement units, so they were normalized before being totaled.

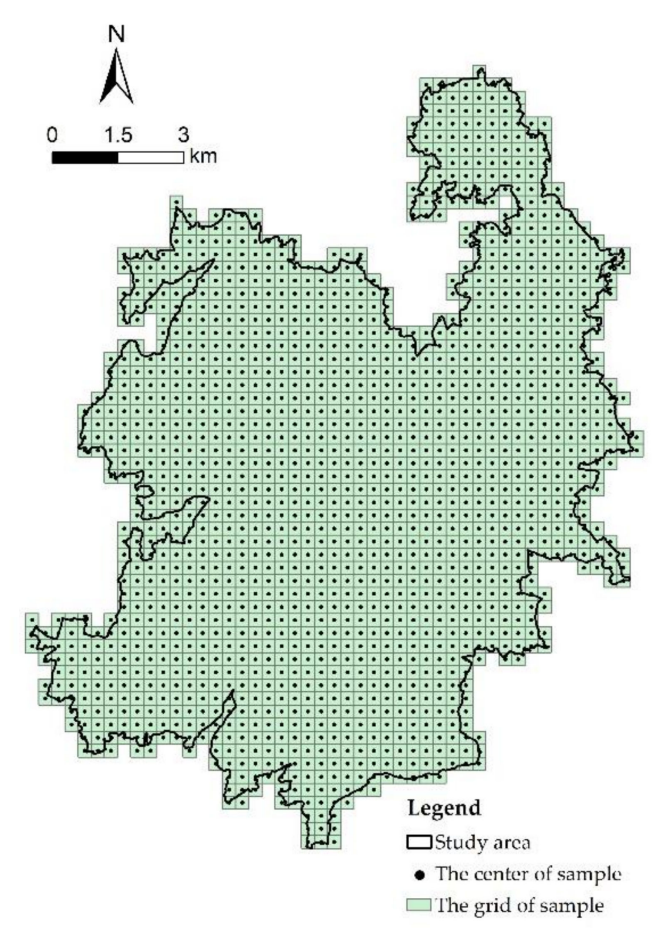

Figure 2. Sample unit of the study area.

Table 1. Carbon density for different land-use types.

\begin{tabular}{cccccc}
\hline & Cultivated Land & Forest Land & Grass Land & Habitation Land & Water \\
\hline $\mathrm{Cv}(\mathrm{tC} \mathrm{ha}-1)$ & 3.25 & 28.11 & 1.24 & 0 & 0 \\
$\mathrm{CS}(\mathrm{tC} \mathrm{ha}-1)$ & 98.3 & 154.2 & 78.8 & 0 & 0 \\
$\mathrm{C}(\mathrm{t} \mathrm{C} \mathrm{ha}-1)$ & 101.55 & 182.31 & 80.04 & 0 & 0 \\
\hline
\end{tabular}

Note: The study applied parameters from existing studies [47] in Zhejiang Province, where the case study area was located.

Table 2. CN indexes for different land-use types.

\begin{tabular}{cccccc}
\hline & Cultivated Land & Forest Land & Grass Land & Habitation Land & Water \\
\hline$C N$ & 97.3 & 80.6 & 93.1 & 100 & 0 \\
\hline
\end{tabular}

Note: The study applied parameters from existing studies [48] performed in the general case study area. 
Table 3. Vegetation indexes for different land-use types.

\begin{tabular}{cccccc}
\hline & Cultivated Land & Forest Land & Grass Land & Habitation Land & Water \\
\hline$V$ & 0.19 & 0.38 & 0.34 & 0.09 & 0 \\
\hline
\end{tabular}

Note: The study applied parameters from existing studies [46] performed in the general case study area.

\subsection{Data Sources}

The data on the territorial boundaries of the traditional villages in the case study area, and the locations of each settlement, were obtained from the Lishui Municipal Housing and Construction Bureau 2017. The data about new geological hazards in 2020 for the case study area were obtained from the Songyang Bureau of Land and Resources. Furthermore, the Landsat TM images, with a $10 \mathrm{~m}$ resolution, for the case study areas in 2010 and 2019 served as the basic data, which originated from the Resources and Environmental Data Cloud Platform (www.resdc.cn (accessed on 20 March 2020)). The land-use maps of the two years were generated through visual interpretation and field verification. The land-use types were divided into five categories: cultivated land, forest land, grassland, habitation land, and water areas. During the field verification of land-use classification in 2019, to obtain more accurate results, 120 GPS points ( 5 points per village) were selected from 24 villages in the case study area for on-site calibration using interviews. Regarding each GPS point, we asked the local villagers about its historical land use of 2010 and surveyed the existing land-use conditions. Based on this, we numbered the 120 GPS points and registered their land-use types in 2010 and 2019, generating a data set of survey and interview's land-use type. Then, we extracted the land-use type of 120 points in the map through remote sensing translation and compared it with the data of survey and interview. It was found that the coincidence rate was as high as $88 \%$, which ensured the accuracy of the land-use map.

\section{Results}

\subsection{Spatial-Temporal Variation Characteristics of Land-Use Types}

The land-use map of the study area with the 24 traditional village clusters in 2010 and 2019 is shown in Figure 3. In contrast with urban regions, there was a high proportion of nature in this area, dominated by forest $(84.81 \%, 2019)$ and followed by cultivated land $(13.49 \%, 2019)$. The inhabited land accounted for a very small proportion of the land area (only $0.75 \%$, 2019). Large tracts of forest land were mainly distributed in the mid-south, while cultivated land was scattered in the middle, north-central, and southwest of the area.
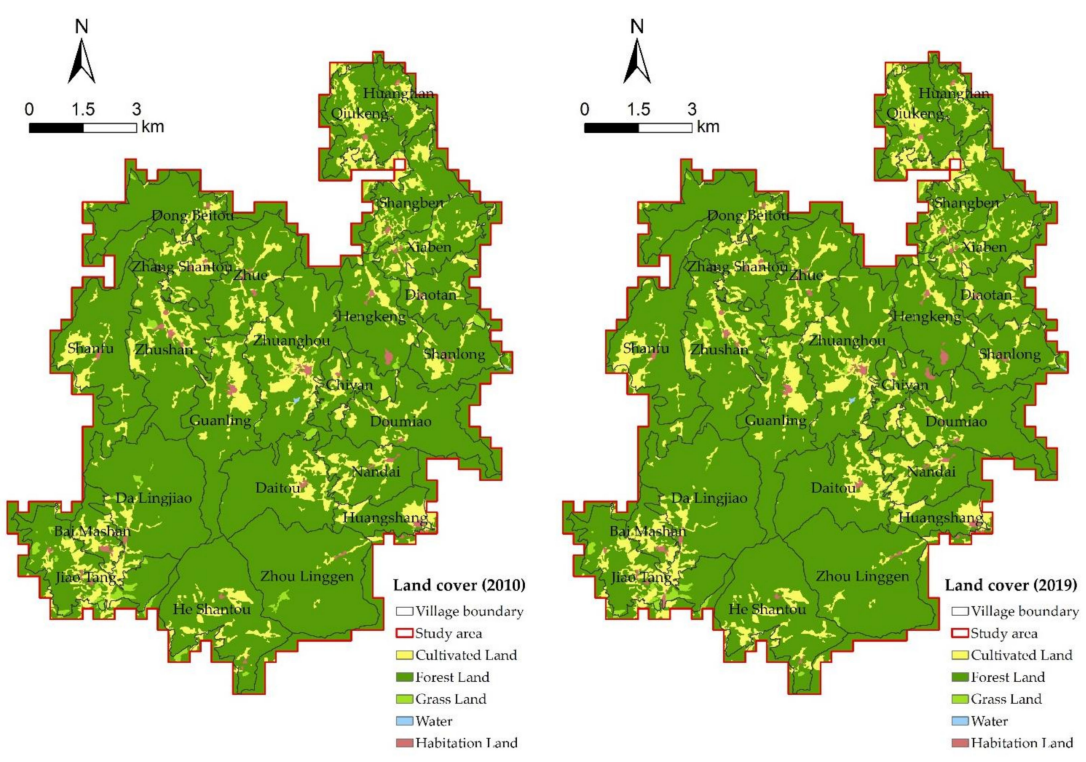

Figure 3. Land-use map of the study area in 2010 and 2019. 
The land use showed small changes from 2010 to 2019 (Figure 4). The conversion area accounted for $3.18 \%$ of the total, with a single area conversion between 0.01 and 17.3 ha. The matrix statistics of transition are shown in Table 4 . The change was mainly concentrated at the junction of the borders of six villages in the eastern central area. The other conversions were scattered. From 2010 to 2019, the transition was dominated by changes from forest land to cultivated land (144.74 ha, accounting for $1.17 \%$ of forest land), followed by the conversion of grassland to forest land ( 42.79 ha, accounting for $22.25 \%$ of the original grassland). A very small amount of grassland was converted to cultivated land (17.76 ha, accounting for $8.98 \%$ of grassland), and there was some conversion from cultivated land to forest land ( 5.39 ha, accounting for $0.3 \%$ of cultivated land).

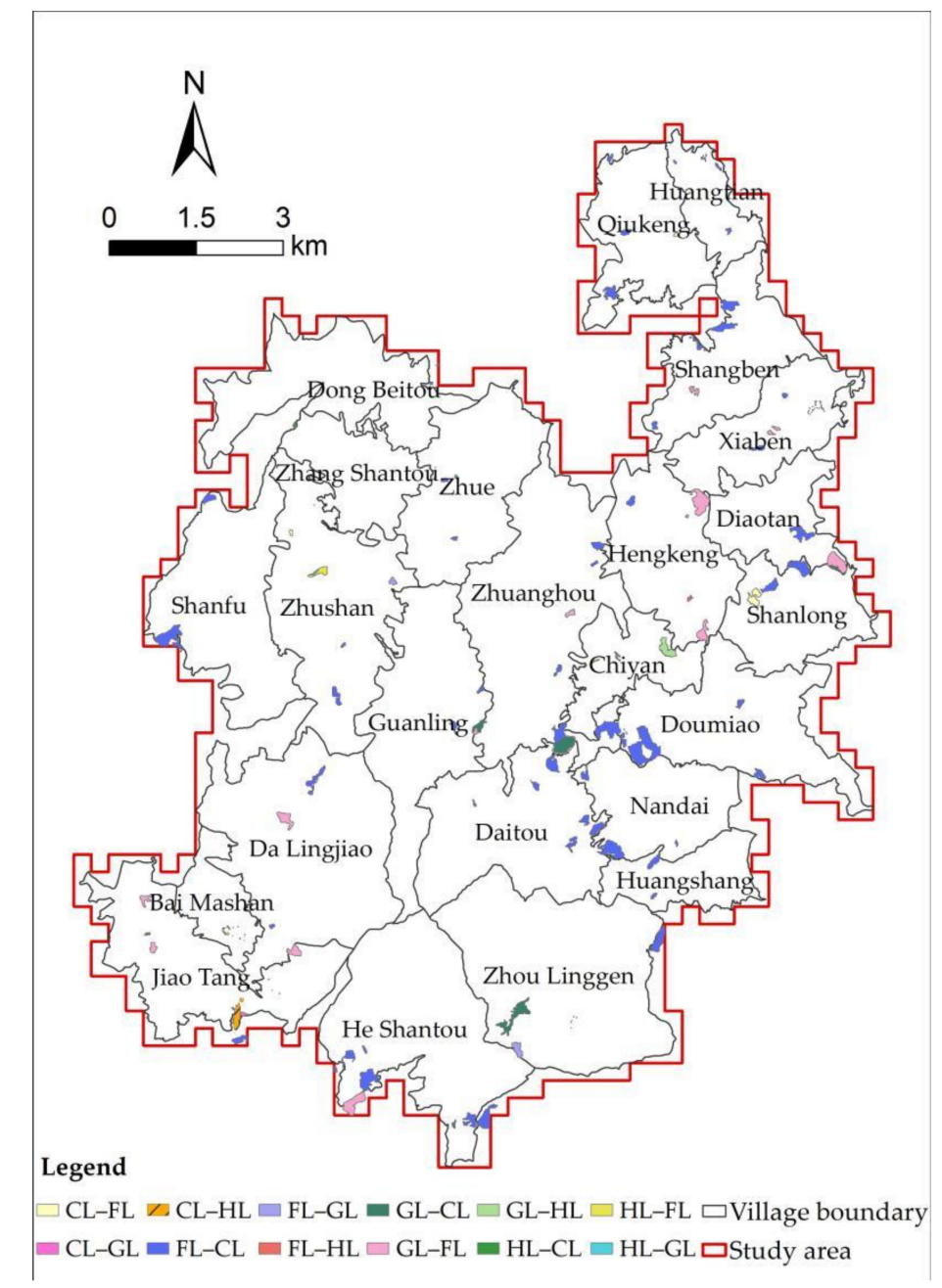

Figure 4. Change in land use in the study area from 2010 to 2019. Note: CL, cultivated land; FL, forest land; GL, grass land; HL, habitation land; CL-FL means land use from CL to FL; CL-GL means land use from CL to GL; CL-HL means land use from CL to HL; FL-CL means land use from FL to CL; FL-GL means land use from FL to GL; FL-HL means land use from FL to HL; GL-CL means land use from GL to CL; GL-FL means land use from GL to FL; GL-HL means land use from GL to HL; HL-CL means land use from HL to CL; HL-FL means land use from HL to FL; HL-GL means land use from HL to GL.

\subsection{Spatial-Temporal Variability Characteristics of the LER}

\subsubsection{LER Calculation and Classification}

After calculating the $L E R$, the natural breakpoint method [49] was used to divide them into five grades, from low to high. After that, the spatial distribution maps associated with 
different ecological risk grades in 2010 and 2019 in the case study area were generated using ArcGIS 10.6 (Figure 5). Table 5 shows that the LER in the TVCA ranged between 0.13 and 0.95 ; more than $34.92 \%$ of the area indicated a medium or higher risk. The overall risk was relatively low, with low risk and medium-low risk playing a dominant role, accounting for $35.46 \%$ and $29.62 \%$, respectively, in 2019 . There were a few high-risk areas, accounting for only $5.5 \%$. From the perspective of the changes between 2010 and 2019, the mean value for the LER showed no significant change (increasing from 0.28 to 0.29 ). However, the areas with high risk and medium-high risk increased slowly in size, at increasing rates of $3.93 \%$ and $4.28 \%$, respectively; and the size of the areas with low-risk levels decreased, at a rate of decrease of $3.24 \%$.

Table 4. Transitions in percentages of the land use from 2010 to 2019 (\%).

\begin{tabular}{|c|c|c|c|c|c|c|c|c|c|}
\hline \multirow{2}{*}{2010} & \multicolumn{5}{|c|}{2019} & \multirow{2}{*}{ Total(2010) } & \multirow{2}{*}{ Loss } & \multirow{2}{*}{$\begin{array}{c}\text { Net Gainin } \\
2019\end{array}$} & \multirow{2}{*}{$\begin{array}{c}\text { Changes in } \\
2019\end{array}$} \\
\hline & Cultivated Land & Forest Land & Grass Land & Water & Habitation Land & & & & \\
\hline $\begin{array}{c}\text { Cultivated } \\
\text { land }\end{array}$ & 12.364 & 0.037 & 0.005 & 0 & 0.028 & 12.43 & 0.07 & 1.06 & 8.51 \\
\hline Forest land & 0.999 & 84.449 & 0.037 & 0 & 0.004 & 85.49 & 1.04 & -0.68 & -0.80 \\
\hline Grass land & 0.119 & 0.295 & 0.88 & 0 & 0.032 & 1.33 & 0.45 & -0.40 & -30.26 \\
\hline Water & 0 & 0 & 0 & 0.024 & 0 & 0.02 & 0 & 0 & 0 \\
\hline $\begin{array}{l}\text { Habitation } \\
\text { land }\end{array}$ & 0.011 & 0.024 & 0.004 & 0 & 0.689 & 0.73 & 0.04 & 0.03 & 3.5 \\
\hline Total (2019) & 13.49 & 84.81 & 0.93 & 0.02 & 0.75 & 100 & & & 8.51 \\
\hline gain & 1.13 & 0.36 & 0.05 & 0 & 0.06 & & & & -0.80 \\
\hline
\end{tabular}
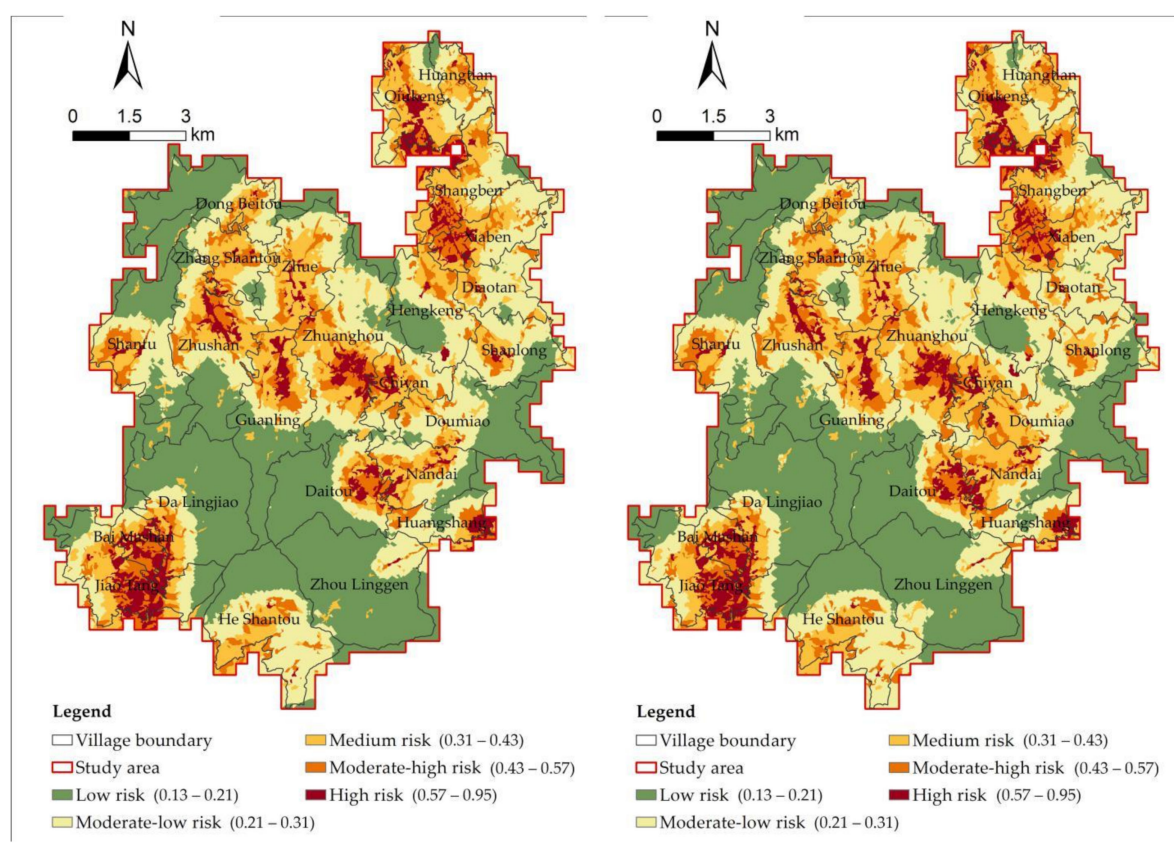

Figure 5. The spatial pattern of the grade of LER from 2010 to 2019.

Table 5. Transitions in the grade of the LER from 2010 to 2019.

\begin{tabular}{|c|c|c|c|c|c|c|}
\hline \multirow[b]{2}{*}{ Grade } & \multirow[b]{2}{*}{ Intervals } & \multicolumn{2}{|c|}{2010} & \multicolumn{2}{|c|}{2019} & \multirow[b]{2}{*}{$\begin{array}{l}\text { Rate of } \\
\text { Increase }\end{array}$} \\
\hline & & Area (ha) & $\begin{array}{c}\text { Percentage } \\
(\%)\end{array}$ & Area (ha) & $\begin{array}{c}\text { Percentage } \\
(\%)\end{array}$ & \\
\hline high & $0.57-0.95$ & 767.29 & 5.3 & 797.46 & 5.5 & $3.93 \%$ \\
\hline medium-high & $0.43-0.57$ & 1500.15 & 10.35 & 1564.42 & 10.8 & $4.28 \%$ \\
\hline medium & $0.31-0.43$ & 2653.09 & 18.31 & 2698.27 & 18.62 & $1.70 \%$ \\
\hline medium-low & $0.21-0.31$ & 4259.03 & 29.39 & 4291.7 & 29.62 & $0.77 \%$ \\
\hline low & $0.13-0.21$ & 5310.44 & 36.65 & 5138.15 & 35.46 & $-3.24 \%$ \\
\hline total & $0.13-0.95$ & 14490 & 100 & 14,490 & 100 & \\
\hline
\end{tabular}


The rate of change in the LER from 2010 to 2019 ranged from $-65.13 \%$ to $179.88 \%$. In this study, the rate of change was divided into six grades from low to high (Figure 6). The risk grade in most areas remained unchanged $(81.97 \%)$; in a small number of areas $(2.98 \%)$, the risk was increased; and in a very small percent of areas $(0.35 \%)$, the risk significantly increased. The grade distribution diagram illustrating the rates of change was generated in ArcGIS (Figure 7). Overall, the risk increased in the southern and central districts and slightly decreased in the southwest and northeast. Areas with a significant increase in risk deserve special attention and are mainly distributed in five villages: Dalingjiao, Zhushan, Diaotan, Doumiao, and Zhuanghou Village.

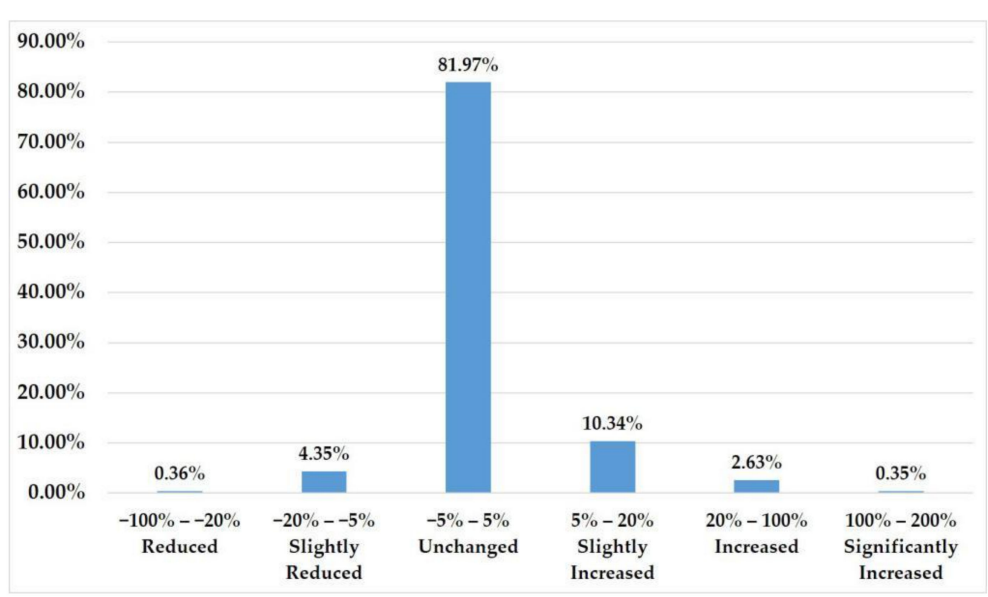

Figure 6. The grade of the rate of change in the LER from 2010 to 2019.

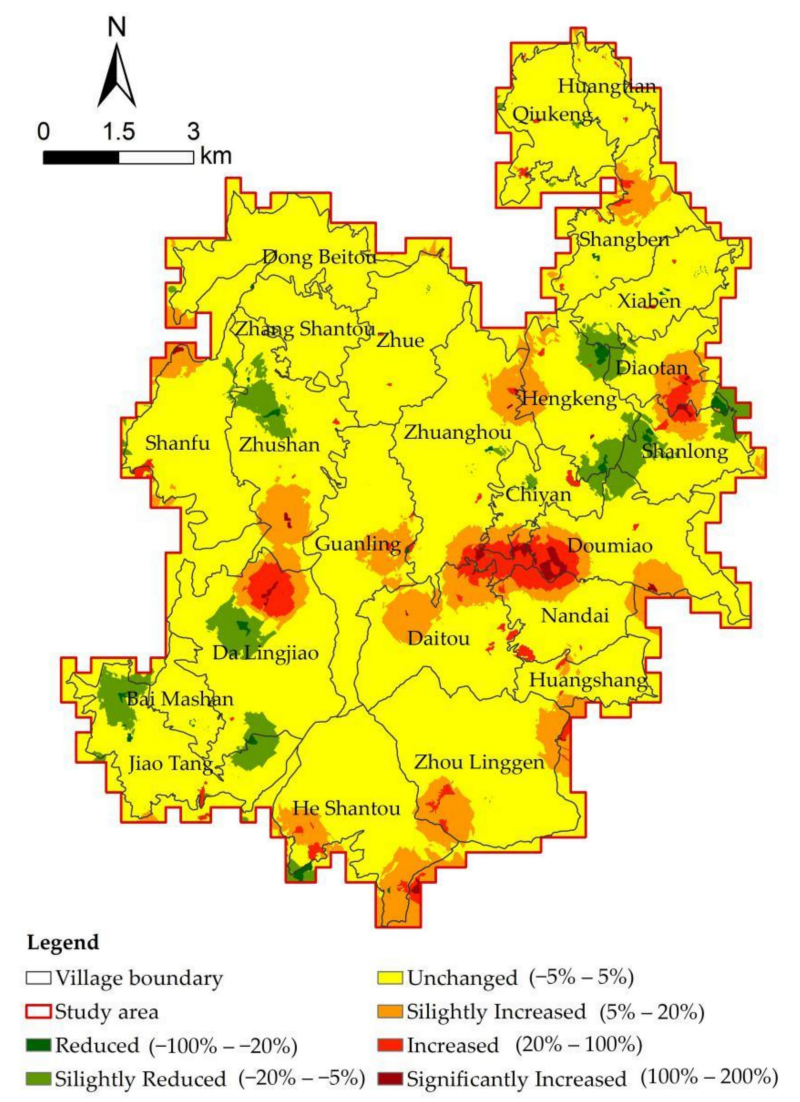

Figure 7. The spatial pattern of the grade of LER change from 2010 to 2019. 


\subsubsection{Change Characteristics of the Indexes}

According to the method of calculating $L E R$, there were six main indexes: $D F, D D$, $D L, C S, V C$, and $C N$. These indexes had different units. After they were normalized, the degree of variation in the mean of each index was counted (Table 6, Figure 8). The risk values for $D L$ and $V C$ increased the most in the case study area. This indicated that the anti-interference ability and air conditioning ability of $E S$ in the area decreased more, and that these are indexes that require the most attention for improvements. The increased amplitudes of the risk values for $D F, D D$, and CS followed, indicating that the stability and the continuity of $E S$, and the carbon sequestration capacity were slightly decreased. As such, these three indicators can be taken as indexes of secondary needed improvement. Meanwhile, the $C N$ showed no significant change, indicating that there was no significant change in the risk associated with the water regulation function.

Table 6. Changes in the indexes of the ER.

\begin{tabular}{ccccccc}
\hline & $\mathbf{C 1}$ & $\mathbf{C 2}$ & $\mathbf{C 3}$ & $\mathbf{C 4}$ & $\mathbf{C 5}$ & $\mathbf{C 6}$ \\
\hline Average risk & $D F$ & $D D$ & $D L$ & $C S$ & $V C$ & $C N$ \\
2010 & 0.210 & 0.316 & 0.242 & 0.070 & 0.071 & 0.832 \\
2019 & 0.216 & 0.308 & 0.261 & 0.073 & 0.076 & 0.833 \\
Change rate & $2.34 \%$ & $1.68 \%$ & $7.88 \%$ & $3.85 \%$ & $7.27 \%$ & $0.16 \%$ \\
\hline
\end{tabular}

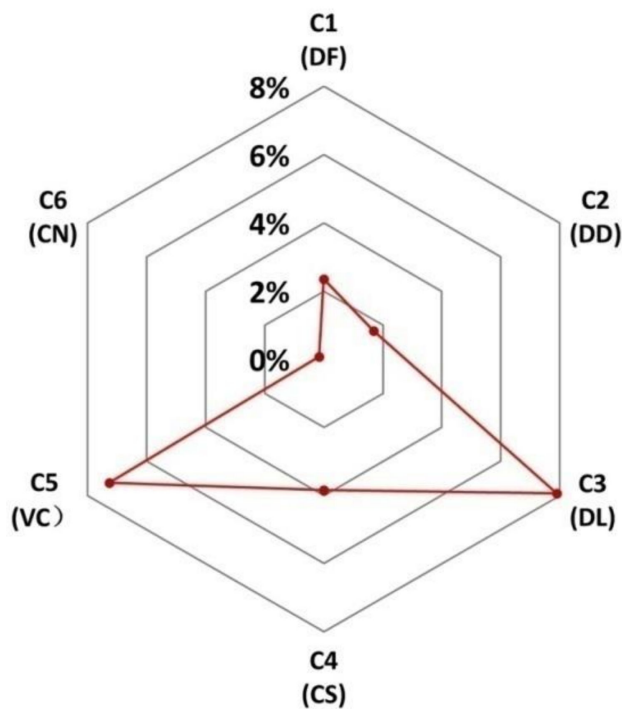

Figure 8. The change in the indexes of average risk.

\subsection{Ecological Risk Identification of Settlement Area}

There were 34 traditional village settlements in the study area. Settlements were considered to be sensitive to areas with increased ecological risks less than $600 \mathrm{~m}$ away [29]. In these ranges, they were vulnerable to the direct influence of ecological disasters. Given this, ArcGIS 10.6 was used to delimit the ecologically sensitive area within $600 \mathrm{~m}$ around the area with increased ecological risk. After calculation (Figure 9), we found 22 settlements in this sensitive area, accounting for $70.59 \%$ of all settlements. These residential areas were considered to be vulnerable to ecological disasters and would benefit from the prevention and control of ecological risks. They were distributed in 16 traditional administrative villages. Of these, Zhupen and Doumiao Village were the villages with the most settlements in the ecologically sensitive areas and can be considered key administrative villages for risk prevention and control. 


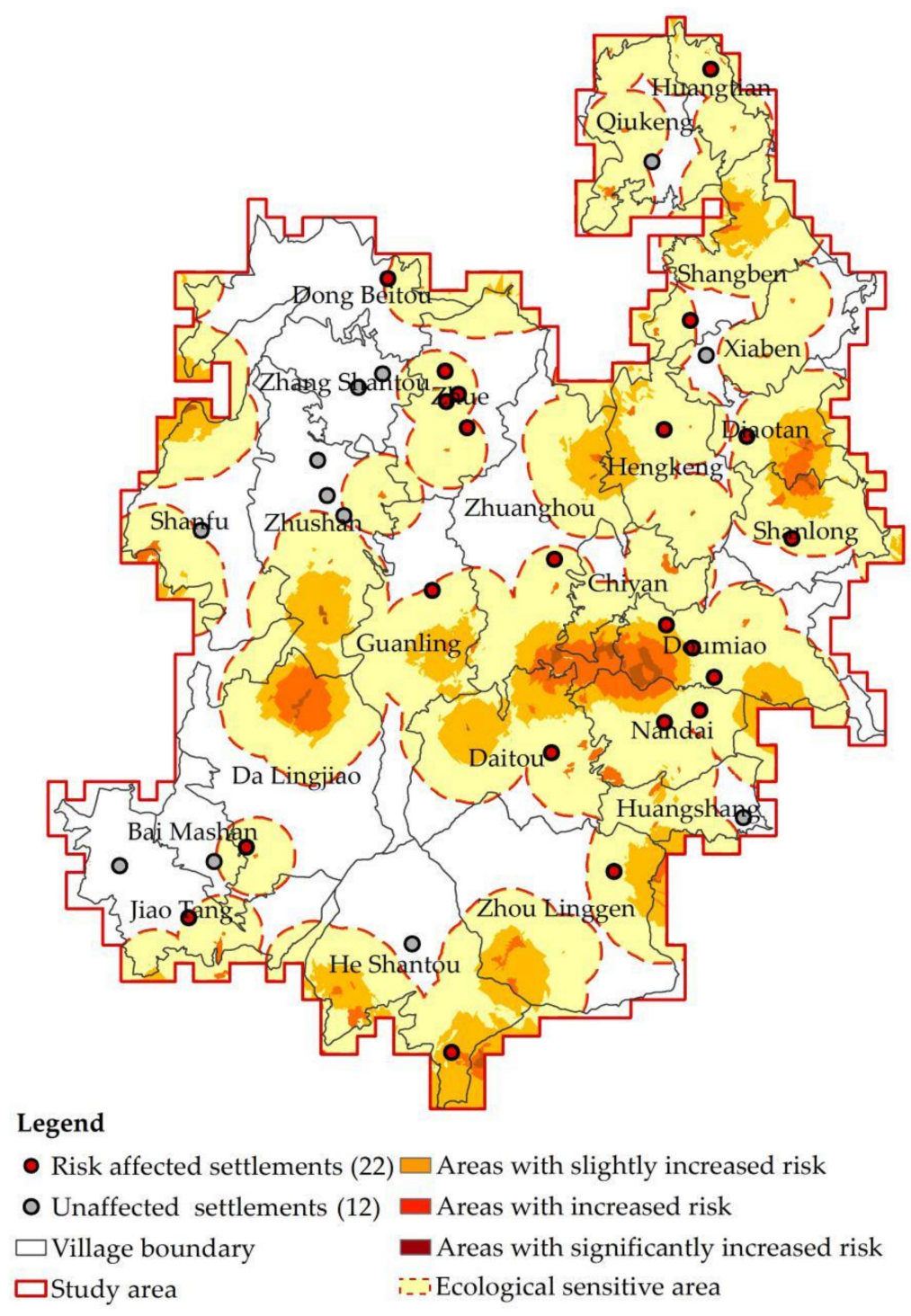

Figure 9. Settlements affected by ecological risk change.

\subsection{Validation for the LER}

Increased ecological risks can lead to the increase of natural disasters [50,51]. Therefore, in the study, the accuracy of the dynamic ecological risk assessment was verified through the dynamic monitoring of the actual locations for additional natural disasters after the termination year (2019). Specifically, based on the map of the spatial pattern of the grade of ecological risk change, the locations of geological hazards in 2020 were superimposed as a test (Figure 10). We discovered that the 16 newly added small-scale geological hazard points were close to the area with increased risk evaluated by this research, between 86 and $832 \mathrm{~m}$. Among them, 14 geological hazard points, $87.5 \%$, were within the sensitive range $(600 \mathrm{~m})$ of the increased risk area. This indicated the evaluation was accurate and that this method could effectively provide a basis for early warnings of geological hazards. 


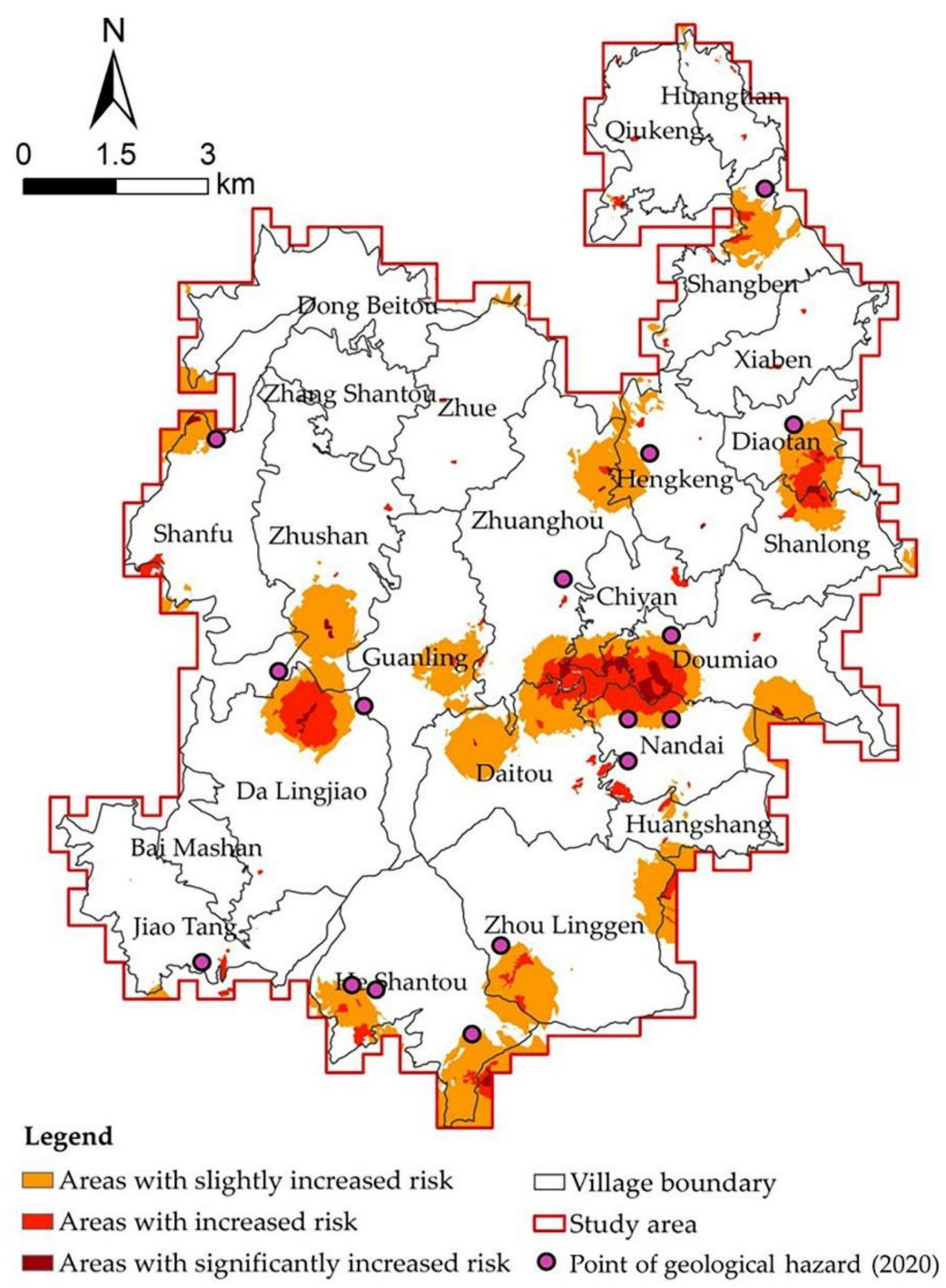

Figure 10. The locations of geological hazards in 2020.

\section{Discussion}

4.1. Methodological Advantages of Integrating the Structure and Function of Landscape Ecosystems in Evaluation

The physical stability of ES in TVCA is important for preserving the inheritance of traditional ecological civilization. The self-regulating EF is also of significance for the development of effective sustainable ecosystems in villages. However, the existing evaluation methods, multiplied by the corresponding vulnerability coefficient based on the calculation of land use, only reflect changes in the final comprehensive ecological risk [27]. They do not separately represent the specific performance changes in $E S$ and $E F$. Therefore, from the perspectives of ecosystem structure and function, this study used six indexes of $D F, D D, D L, C S, V C$, and $C N$ to represent different aspects of landscape ecosystems. The indexes can measure the overall change in ecological risk after weighted summation and can separately analyze the change of each character for its ecosystem structure and function. Given this, three bases were provided for the ecological decision making and management of TVCA: (1) overall LER prevention and control; (2) differentiated index improvement in the $E S$ and $E F$; and (3) the inheritance of the traditional ecological civilization and ensuring sustainable landscape ecosystems. 


\subsection{Causes of Differences in Risks}

Comparing Figure 3; Figure 7 shows that in the areas with significantly increased risks, the conversion of land use was mainly from forest land to cultivated land. In the areas with decreased risks, the conversion was mainly from grassland to forest land. This indicated that the increase of risks in these local areas might be more strongly correlated to the conversion from forest land to cultivated land. The decrease in risks may be related to the conversion from grassland to forest land. Through further observation, we found that the areas where the risk increases or decreases mostly occur on the village boundary. This implied that this traditional village cluster has implemented different land-use strategies, especially in the village boundary area.

First, some villages have strictly followed the coordinated strategy and environment protection requirements of national-level traditional villages stipulated by the Bureau of Housing and Urban-Rural Development, keeping their land use unchanged. Second, in some villages, policy for afforestation, stipulated by the provincial forestry department, has been adopted to receive subsidies, leading to some grasslands in the mountainous areas being converted into timbered forests after 10 years of environmental cultivation. Third, some villages have had weak awareness levels related to ecological protection. Based on the need for the economic increase, these villages adopted the policies of BALS and RLCQ trade, and performed deforestation for farmland construction near the settlements, to gain extra fiscal revenue from trading out the newly added cultivated land quotas [7,52].

These results indicated that the policy differences and synergistic loopholes might be an indirect driver for the differentiation of ecological risks in the TVCA. In Eastern China, which has scarce land resources, the RLCQ trade is 360,000 yuan per mu at the municipal level in the case study area and 200,000 yuan per mu in the corresponding county. Except for the reclamation fee, villagers in the village with the newly cultivated land quotas received 600 yuan per mu [53]. However, the subsidy for afforestation in barren mountains in the case study area is only 300 yuan per mu [54], far less than the fiscal revenue from trading cultivated land quotas.

TVCA are often the areas with rich forest resources, underdeveloped economies, and low industrial vitality. Therefore, many villages have been willing to achieve economic growth through RLCQ trade and have converted forest land to farmland; however, that can easily result in non-negligible landscape ecological risks. Thus, adjustments and synergies concerning land-use policies, fiscal revenue, and different management methods are still needed for TVCA to reduce the local ecological risk.

\subsection{Limitations and Future Work}

When quantifying the $E F$, we used multiple ecological coefficient values of each landuse type. In the evaluation of county or city scale, such as this study area, these ecological coefficients are feasible to use as they are usually spatially homogeneous. However, when the assessment scale is very large, such as provincial scales, these coefficients will contain spatial differences and affect the accuracy of the results. Thus, this approach needs to be further improved when quantifying TVCA in a very large-scale region with these ecological coefficients of obvious spatial heterogeneity. Additionally, when quantifying the $E S$, we did include the biotic elements. Thus, future studies could further integrate more biological factors, making the evaluation of the ecosystem more complete. Finally, the potential direct and indirect causes were qualitatively discussed, but the study did not include quantitative research on the influencing factors. Thus, future studies could scientifically explore the causes and mechanisms influencing the differences in LER from multiple perspectives, including natural, geographical, economic, industrial, and social factors.

\section{Conclusions}

In-depth research has been conducted to dynamically assess the LER; however, for traditional villages, there has been no assessment relating to it. To fill this gap, this study provided a practical evaluative method to the scientific classification of LER in TVCA. Based 
on land-use changes, this study integrated ecosystem structure and function, constructing an evaluation method covering six indexes. The clustering area for the study included 24 state-level traditional villages in Songyang County of Lishui, Zhejiang Province of China, and the ecological risk assessment was conducted for the years 2010-2019.

The results showed that the land-use transition was subtle but dominated by changes from forest to cultivated land, posing high risk and medium-high risk which increased slowly in size. Additionally, significantly increased risks were located mainly in the boundary area of the five villages. Moreover, $D L$ and $V C$ decreased the most and are the indexes requiring the most attention for improvements. Finally, 22 settlements were found in the sensitive area with increased risks less than $600 \mathrm{~m}$ away. The measured areas with increased risk in the study were also highly consistent with the newly added geological hazard points after the termination of the year for monitoring. This indicated that this method was accurate and may be effective as a basis for early warnings of geological disasters.

The main contribution of this study is as follows: Firstly, the features of the LER in TVCA of the study area were explored, providing scientific value for traditional villages' risk prevention and ecosystem protection. Secondly, the assessment method based on land-use change calculation can also be applied to other areas with traditional village clusters as a scientific basis for investigating the hidden ecological dangers.

Author Contributions: Conceptualization and writing: S.L.; review and editing: M.Y.; data curation and visualization: M.B. All authors have read and agreed to the published version of the manuscript.

Funding: This research was funded by the National Natural Science Foundation of China (grant number 51908495).

Institutional Review Board Statement: Not applicable.

Informed Consent Statement: Not applicable.

Data Availability Statement: All relevant data are within the manuscript.

Acknowledgments: The authors thank the teachers and students from Zhejiang University City College who participated in the field verification of land-use type.

Conflicts of Interest: The authors declare no conflict of interest.

\section{References}

1. Guo, Z.; Sun, L. The planning, development and management of tourism: The case of Dangiia, an ancient village in China. Tour. Manag. 2016, 56, 52-62. [CrossRef]

2. Na, L.; Li, M.; Zheng, N.; Han, C. Contiguous Application Area in the Protection of Traditional Villages in Jingxing County in the Central Area of the Traditional Village Planning Protection as an Example. Dev. Small Cities Towns 2017, 1, 83-88.

3. Olwig, K.R. Recovering the substantive nature of landscape. Ann. Assoc. Am. Geogr. 1996, 86, 630-653. [CrossRef]

4. Turner, M.G.; Gardner, R.H.; O'neill, R.V.; O'Neill, R.V. Landscape Ecology in Theory and Practice; Springer: New York, NY, USA, 2001; Volume 401.

5. Wilson, E.O.; Forman, R. Land Mosaics: The ecology of Landscape and Regions; Cambridge University Press: Cambridge, UK, 1995.

6. Yuncai, W.; Yishao, S.; Tian, C. Research progress and prospects of traditional territory cultural landscape. J. Tongji Univ. 2009, 20, 18-24.

7. Xiong, B.; Chen, R.; Xia, Z.; Ye, C.; Anker, Y. Large-scale deforestation of mountainous areas during the 21st Century in Zhejiang Province. Land Degrad. Dev. 2020, 31, 1761-1774. [CrossRef]

8. Wang, J.; Peng, J.; Zhao, M.; Liu, Y.; Chen, Y. Significant trade-off for the impact of Grain-for-Green Programme on ecosystem services in North-western Yunnan, China. Sci. Total Environ. 2017, 574, 57-64. [CrossRef]

9. Ouyang, C.; Zhao, W.; Xu, Q.; Peng, D.; Li, W.; Wang, D.; Zhou, S.; Hou, S. Failure mechanisms and characteristics of the 2016 catastrophic rockslide at Su village, Lishui, China. Landslides 2018, 15, 1391-1400. [CrossRef]

10. Chapin, F.S., III; Matson, P.A.; Mooney, H.A. Principles of Terrestrial Ecosystem Ecology; Springer Science \& Business Media: New York, NY, USA, 2011.

11. Jacobides, M.G.; Cennamo, C.; Gawer, A. Towards a theory of ecosystems. Strateg. Manag. J. 2018, 39, 2255-2276. [CrossRef]

12. Jónsson, J.Ö.G.; Davíðsdóttir, B. Classification and valuation of soil ecosystem services. Agric. Syst. 2016, 145, 24-38. [CrossRef]

13. Klijn, J. Hierarchical Concepts in Landscape Ecology and Its Underlying Disciplines; Report 100; DLO Winand Staring Centre: Wageningen, The Netherlands, 1995. 
14. Urban, D.L.; O’Neill, R.V.; Shugart, H.H., Jr. A hierarchical perspective can help scientists understand spatial patterns. BioScience 1987, 37, 119-127. [CrossRef]

15. Hunsaker, C.T.; Graham, R.L.; Suter, G.W.; O’Neill, R.V.; Barnthouse, L.W.; Gardner, R.H. Assessing ecological risk on a regional scale. Environ. Manag. 1990, 14, 325-332. [CrossRef]

16. Bormann, F. Landscape ecology and air pollution. In Landscape Heterogeneity and Disturbance; Springer: New York, NY, USA, 1987; pp. 37-57.

17. Bartell, S. Ecological risk assessment. In Encyclopedia of Ecology; Elsevier BV: Amsterdam, The Netherlands, 2008.

18. Turner, M.G.; Gardner, R.H. Quantitative Methods in Landscape Ecology; Springer: New York, NY, USA, 1991.

19. Xi, J.; Zhao, M.; Ge, Q.; Kong, Q. Changes in land use of a village driven by over 25 years of tourism: The case of Gougezhuang village, China. Land Use Policy 2014, 40, 119-130. [CrossRef]

20. Käyhkö, N.; Fagerholm, N.; Asseid, B.S.; Mzee, A.J. Dynamic land use and land cover changes and their effect on forest resources in a coastal village of Matemwe, Zanzibar, Tanzania. Land Use Policy 2011, 28, 26-37. [CrossRef]

21. Elbakidze, M.; Angelstam, P. Implementing sustainable forest management in Ukraine's Carpathian Mountains: The role of traditional village systems. For. Ecol. Manag. 2007, 249, 28-38. [CrossRef]

22. Bayliss, P.; Van Dam, R.; Bartolo, R. Quantitative ecological risk assessment of the Magela Creek floodplain in Kakadu National Park, Australia: Comparing point source risks from the Ranger Uranium Mine to diffuse landscape-scale risks. Hum. Ecol. Risk Assess. Int. J. 2012, 18, 115-151. [CrossRef]

23. Mann, D.; Anees, M.M.; Rankavat, S.; Joshi, P.K. Spatio-temporal variations in landscape ecological risk related to road network in the Central Himalaya. Hum. Ecol. Risk Assess. Int. J. 2021, 27, 289-306. [CrossRef]

24. Jin, X.; Jin, Y.; Mao, X. Ecological risk assessment of cities on the Tibetan Plateau based on land use/land cover changes-Case study of Delingha City. Ecol. Indic. 2019, 101, 185-191. [CrossRef]

25. Brabec, E.; Chilton, E. Toward an ecology of cultural heritage. Change Over Time 2015, 5, 266-285. [CrossRef]

26. Affek, A.; Degórski, M.; Wolski, J.; Solon, J.; Kowalska, A.; Roo-Zielińska, E.; Grabińska, B.; Kruczkowska, B. Chapter 3-Methods. In Ecosystem Service Potentials and Their Indicators in Postglacial Landscapes; Affek, A., Degórski, M., Wolski, J., Solon, J., Kowalska, A., Roo-Zielińska, E., Grabińska, B., Kruczkowska, B., Eds.; Elsevier: Amsterdam, The Netherlands, 2020; pp. 97-111. [CrossRef]

27. Qiwen, C.; Xiwen, Z.; Hongkun, M.; Jiansheng, W. Review of landscape ecological risk and an assessment framework based on ecological services: ESRISK. Acta Geogr. Sin. 2018, 73, 843-855.

28. Gilroy, J.J.; Edwards, D.P. Source-sink dynamics: A neglected problem for landscape-scale biodiversity conservation in the tropics. Curr. Landsc. Ecol. Rep. 2017, 2, 51-60. [CrossRef]

29. Xu, W.; Wang, J.; Zhang, M.; Li, S. Construction of landscape ecological network based on landscape ecological risk assessment in a large-scale opencast coal mine area. J. Clean. Prod. 2021, 286, 125523. [CrossRef]

30. Yingchun, C.; Yukun, Z. Appraisal and selection of "Chinese traditional village" and study on the village distribution. Archit. J. 2013, 12, 44-49.

31. Cleland, D.T.; Avers, P.E.; McNab, W.H.; Jensen, M.E.; Bailey, R.G.; King, T.; Russell, W.E. National hierarchical framework of ecological units. Ecosyst. Manag. Appl. Sustain. For. Wildl. Resour. 1997, 20, 181-200.

32. Zhang, W.; Wang, W.; Li, X.; Ye, F. Economic development and farmland protection: An assessment of rewarded land conversion quotas trading in Zhejiang, China. Land Use Policy 2014, 38, 467-476. [CrossRef]

33. Foster, D.; Swanson, F.; Aber, J.; Burke, I.; Brokaw, N.; Tilman, D.; Knapp, A. The importance of land-use legacies to ecology and conservation. BioScience 2003, 53, 77-88. [CrossRef]

34. Simmons, J.A.; Currie, W.S.; Eshleman, K.N.; Kuers, K.; Monteleone, S.; Negley, T.L.; Pohlad, B.R.; Thomas, C.L. Forest to reclaimed mine land use change leads to altered ecosystem structure and function. Ecol. Appl. 2008, 18, 104-118. [CrossRef]

35. Turnbull, L.; Wainwright, J.; Brazier, R.E. A conceptual framework for understanding semi-arid land degradation: Ecohydrological interactions across multiple-space and time scales. Ecohydrol. Ecosyst. Land Water Process. Interact. Ecohydrogeomorphol. 2008, 1, 23-34. [CrossRef]

36. Thom, R. Structural Stability and Morphogenesis: An Outline of a General Theory of Models; CRC Press: Boca Raton, FL, USA, 2018.

37. McGarigal, K.; Cushman, S.A.; Ene, E. FRAGSTATS v4: Spatial Pattern Analysis Program for Categorical and Continuous Maps. Computer Software Program Produced by the Authors at the University of Massachusetts, Amherst. 2012. Available online: http://www.umass.\%20edu/landeco/res./fragstats/fragstats.html (accessed on 20 April 2020).

38. McGarigal, K. FRAGSTATS: Spatial Pattern Analysis Program for Quantifying Landscape Structure; US Department of Agriculture: Portland, OR, USA, 1995; Volume 351.

39. Liu, D.; Qu, R.; Zhao, C.; Liu, A.; Deng, X. Landscape ecological risk assessment in Yellow River Delta. J. Food Agric. Env. 2012, 10, 970-972.

40. O'neill, R.; Hunsaker, C.; Timmins, S.P.; Jackson, B.; Jones, K.; Riitters, K.H.; Wickham, J.D. Scale problems in reporting landscape pattern at the regional scale. Landsc. Ecol. 1996, 11, 169-180. [CrossRef]

41. Jie, G.; Caixia, Z.; Yuchu, X.; Yanjing, G. Ecological risk assessment and its management of Bailongjiang watershed, southern Gansu based on landscape pattern. Chin. J. Appl. Ecol. 2014, 25, 2041-2048.

42. Su, H.-M.; He, A.-X. Analysis of land use based on RS and geostatistics in Fuzhou City. J. Nat. Resour. 2010, 25, 91-99.

43. Kang, P.; Chen, W.; Hou, Y.; Li, Y. Linking ecosystem services and ecosystem health to ecological risk assessment: A case study of the Beijing-Tianjin-Hebei urban agglomeration. Sci. Total Environ. 2018, 636, 1442-1454. [CrossRef] [PubMed] 
44. Houghton, R.; Hackler, J. Changes in terrestrial carbon storage in the United States. 1: The roles of agriculture and forestry. Glob. Ecol. Biogeogr. 2000, 9, 125-144. [CrossRef]

45. Natural Resources Conservation Service. Urban Hydrology for Small Watersheds; Technical Release $\mathrm{n}^{\circ}$ 55; Soil Conservation Service: Washington, DC, USA, 1986.

46. Xu, J.; Zhao, H.; Yin, P.; Wu, L.; Li, G. Landscape ecological quality assessment and its dynamic change in coal mining area: A case study of Peixian. Environ. Earth Sci. 2019, 78, 1-13. [CrossRef]

47. Zhang, J.; Ge, Y.; Chang, J.; Jiang, B.; Jiang, H.; Peng, C.; Zhu, J.; Yuan, W.; Qi, L.; Yu, S. Carbon storage by ecological service forests in Zhejiang Province, subtropical China. For. Ecol. Manag. 2007, 245, 64-75. [CrossRef]

48. Zhiyi, W.; Zhiqiang, Y.; Xuejian, Z.; Dongyang, L. Application of SCS model on computing the surface runoff of different land use types-A case study on Yuyao, Zhejiang Province. J. Zhejiang Univ. 2016, 43, 226-230.

49. Jenks, G.F. The data model concept in statistical mapping. Int. Yearb. Cartogr. 1967, 7, 186-190.

50. Wang, H.; Lin, Z.; Xiao, Y.; Lu, H.; Zhang, W.; Zhan, Y.; Yan, Y. Ecological risk assessment of landslide disasters based on potential loss of ecosystem services. Ying Yong Sheng Tai Xue Bao 2019, 30, 3553-3562.

51. Liu, X.; Chen, H. Regional assessment on ecological risk of ecosystems under natural hazards: An application in Guangdong Province (SE China). Nat. Hazards 2020, 100, 205-229. [CrossRef]

52. Bryan, B.A.; Gao, L.; Ye, Y.; Sun, X.; Connor, J.D.; Crossman, N.D.; Stafford-Smith, M.; Wu, J.; He, C.; Yu, D. China's response to a national land-system sustainability emergency. Nature 2018, 559, 193-204. [CrossRef]

53. Yicai. Available online: https://m.yicai.com/news/2742209.html (accessed on 4 February 2020).

54. Shu, B.; Shen, Y.; He, Y.; Zhao, S.; Liu, H. An empirical analysis of forestry subsidies' impact on farmer households' forestry investment in Zhejiang Province. J. Zhejiang AF Univ. 2017, 34, 534-542. 